\title{
Removal of Penicillin G by combination of sonolysis and Photocatalytic (sonophotocatalytic) process from aqueous solution: process optimization using RSM (Response Surface Methodology)
}

\author{
Ali Almasi ${ }^{1}$, Abdollah Dargahi $^{2}$, Mitra Mohamadi $^{3}$, Hamed Biglari $^{4}$, Farhad Amirian ${ }^{5}$, Mehdi Raei $^{6}$
}

${ }^{1}$ Ph.D. of Environmental Health Engineering, Professor, Department of Environmental Health Engineering, Faculty of Health, Social Development And Health Promotion Research Center, Kermanshah University of Medical Sciences, Kermanshah, Iran

${ }^{2} \mathrm{Ph}$.D. Student of Environmental Health Engineering, Department of Environmental Health Engineering, Faculty of Health, Hamadan University Of Medical Sciences, Hamadan, Iran

${ }^{3}$ M.Sc. of Environmental Health Engineering, Department of Environmental Health Engineering, Faculty of Health, Kermanshah University Of Medical Sciences, Kermanshah, Iran

${ }^{4}$ M.Sc. of Environmental Health Engineering, Department of Environmental Health Engineering, School of Public Health, Social Development \& Health Oromotion Research Center, Gonabad University of Medical Sciences, Gonabad, Iran

${ }^{5} \mathrm{Ph} . \mathrm{D}$. Student of Pathology, Department of Pathobiology, Faculty of Medicine, Kermanshah University of Medical Sciences, Kermanshah, Iran

${ }^{6}$ M.Sc. of Biostatistics, Department of Biostatistics, Faculty of Medicine, Qom University of Medical Sciences, Qom, Iran

\section{Type of article: Original}

\begin{abstract}
Introduction: Penicillin $\mathrm{G}(\mathrm{PG})$ is used in a variety of infectious diseases, extensively. Generally, when antibiotics are introduced into the food chain, they pose a threat to the environment and can risk health outcomes. The aim of the present study was the removal of Penicillin G from an aqueous solution through an integrated system of $\mathrm{UV} / \mathrm{ZnO}$ and $\mathrm{UV} / \mathrm{WO}_{3}$ with Ultrasound pretreatment.

Methods: In this descriptive-analytical work dealing with the removal of Penicillin G from an aqueous solution, four significant variables, contact time (60-120 min), Penicillin G concentration (50-150 mg/L), ZnO dose (200$400 \mathrm{mg} / \mathrm{L})$, and $\mathrm{WO}_{3}$ dose $(100-200 \mathrm{mg} / \mathrm{L})$ were investigated. Experiments were performed in a Pyrex reactor (batch, 1 Lit) with an artificial UV 100-Watt medium pressure mercury lamp, coupled with ultrasound (100 W, $40 \mathrm{KHz}$ ) for PG pre-treatment. Chemical Oxygen Demand (COD) was selected to follow the performance of the photo-catalytic process and sonolysis. The experiments were based on a Central Composite Design (CCD) and analyzed by Response Surface Methodology (RSM). A mathematical model of the process was designed according to the proposed degradation scheme.

Results: The results showed that the maximum removal of $\mathrm{PG}$ occurred in ultrasonic/UV/ $/ \mathrm{WO}_{3}$ in the presence of $50 \mathrm{mg} / \mathrm{L} \mathrm{WO}_{3}$ and contact time of 120 minutes. In addition, an increase in the PG concentration caused a decrease in COD removal. As the initial concentration of the catalyst increased, the COD removal also increased. The maximum COD removal (91.3\%) achieved by $200 \mathrm{mg} / \mathrm{L} \mathrm{WO}$ and $400 \mathrm{mg} / \mathrm{l} \mathrm{ZnO}$, a contact time of 120 minutes, and an antibiotic concentration of $50 \mathrm{mg} / \mathrm{L}$. All of the variables in the process efficiency were found to be significant $(\mathrm{p}<0.05)$. Catalyst dose and contact time were shown to have a positive effect on the response $(\mathrm{p}<$ $0.05)$.

Conclusion: The research data supported the conclusion that the combination of advanced oxidation process of sonolysis and photocatalytic (sonophotocatalytic) were applicable and environmentally friendly processes, which preferably can be applied extensively.

Keywords: Integrated process, Penicillin G, Advanced oxidation, COD removal, Response Surface Methodology
\end{abstract}

\section{Corresponding author:}

Mitra Mohammadi, Department of Environmental Health Engineering, Faculty of Health, Kermanshah University Of Medical Sciences, Kermanshah, Iran. Tel: +98.8334244779, Email: m.mohamadi725@gmail.com

Received: April 11, 2016, Accepted: June 27, 2016, Published: September 2016 iThenticate screening: May 01, 2016, English editing: July 28, 2016, Quality control: August 06, 2016

(C) 2016 The Authors. This is an open access article under the terms of the Creative Commons Attribution-NonCommercialNoDerivs License, which permits use and distribution in any medium, provided the original work is properly cited, the use is non-commercial and no modifications or adaptations are made. 


\section{Introduction}

Recently, the pharmaceutical drug presence in the environment is considered as a noteworthy environmental concern worldwide (1). Antibiotics are one of the most important groups of pharmaceuticals that are commonly used in human infections, veterinary medicine, and agriculture. Meanwhile the harmful effect of antibiotics in the environment, including release into soil, surface water, and creating biological resistance are undeniable (2). The annual antibiotic consumption in the world has been estimated at around between 100000-200000 tons (3). Approximately, 90\% antibiotics after their use are active in the human body. Therefore, it can be deduced optimistically that nearly 30,000 tons and at worse, approximately 180,000 tons of active antibiotics are being introduced into the environment, annually $(4,5)$. The presence of antibiotics has been detected in surface waters, ground water aquifers, and even in drinking water in a range of nanogram/L to microgram/L, which have been released into environment by various pathways, such as the pharmaceutical industry's wastewater, hospitals, as well as human and animal elimination $(6,7)$. The main purpose of evaluation and control of pharmaceuticals in the environment is the release of antibiotics into food chain and the building of pharmaceutical drug resistance, which threatens the environment and human health. Penicillin $\mathrm{G}\left(\mathrm{C}_{16} \mathrm{H}_{17} \mathrm{~N}_{2} \mathrm{NaO}_{4} \mathrm{~S}\right)$ is used for diverse category of infectious diseases, generally, it has a biological half-life of 30-60 minutes and is is completely water soluble. Penicillin G (PG) prevents the production of peptidoglycan though the destruction of the bacterial cell-wall (8). Up to now, various physical, chemical, and biological methods have been utilized for the removal of pharmaceutical drugs from an aqueous solution $(9,10)$. In recent decades, an advanced oxidation process (AOPs) has been experienced widespread use, in order to reduce antibiotic residue in aqueous solutions. Advanced oxidation processes have become more advanced including, combination of processes such as ozonation, peroxide process, wet oxidation, $\mathrm{H}_{2} \mathrm{O}_{2}$ /ozonation/ultraviolet, photocatalytic, and sonolytic processes. (11-13). Generally, AOPs processes are more acceptable for wastewater containing pharmaceutical drugs in comparison to other technologies because it is able to completely remove allof the pharmaceutical drug compounds (14). Among the advanced photo oxidation processes, non-homogenous photocatalyst has been employed as an applicable technique for the degradation of contaminants, such as ultrasound/photocatalytic that has come to be known as the sonophotocatalytic degradation process $(15,16)$. The sonochemical being able to achieve the oxidation of the antibiotics and then, be converted into byproducts that have a lower toxicity and that are harmless for microorganisms. (17). Ultrasound radiation enhances the chemical and physical processing in an aqueous solution and the collapse of bubble cavitation, subsequently (18). The main objective of this study was to investigate the removal of PG by a combination of the advanced oxidation process of ultrasound (sonolysis) and the photocatalytic process (UV/ZnO and $\mathrm{UV} / \mathrm{WO}_{3}$ ). The present study modeled and analyzed the removal of PG from an aqueous solution by Response Surface Methodology (RSM).

\section{Material and Methods}

\subsection{Study design}

This descriptive-analytical study was conducted beginning October 2015 until December 2015 at Kermanshah University of Medical Science, Kermanshah, Iran.

\subsection{Chemical}

All chemicals used were of analytical reagent grade and were used without any further purification. Penicillin G, Zinc Oxide $(\mathrm{ZnO})$, and Tungsten Trioxide $\left(\mathrm{WO}_{3}\right)$ were purchased from Merck Company, Germany. Synthetic solutions were prepared with deionized water.

\subsection{Collection of samples and the operation of the ultrasound and photocatalytic reactor}

The variables in this study were contact time (60-120 min), initial PG concentration (50-150 mg/L), ZnO dose (200$400 \mathrm{mg} / \mathrm{L})$, and $\mathrm{WO}_{3}$ dose $(100-200 \mathrm{mg} / \mathrm{L})$. All of experiments were carried out in batch mode with 3 repetitions. To reduce the data scattering, the mean value of experiments were reported. The Pyrex reactor was designed and fabricated with a working volume of 1 liter. In order to investigate the effects of the ultrasound, the whole reactor assembly was immersed into an ultrasonic bath (DSA 100-SK 2-4, 0) having the capacity of 4 liters and with a submersed contact time of 60 minutes $\left(100 \mathrm{~W}, 40 \mathrm{KHz}, 30^{\circ} \mathrm{C}\right)$. The efficiency of ultrasonic was evaluated by Chemical Oxygen Demand (COD) measurement. For the following step, the PG solution was blended by a magnetic stirrer during the reaction period (at a velocity of $500 \mathrm{rpm}$ ). The synthetic wastewater was introduced batch by batch into the reactor. The irradiation source was a low pressure mercury lamp with a wavelength of $254 \mathrm{~nm}$ (Philips Co, Germany) that had been adjusted at $5 \mathrm{~cm}$ above of reactor and was surrounded with aluminium foil. The measurement of the concentrations of chemical oxygen demand (COD) were carried according to the standard methods of water and wastewater analysis (19). For the COD, a colorimetric technique with a closed reflux method 
was developed. Spectrophotometer (DR 5000, Hach, Jenway, USA) at $600 \mathrm{~nm}$ wavelength was used to measure the absorbance of the COD samples. The experimental runs were designed using Design Expert Software (DOE) (StatEase Inc., version 6.0) as described in Section 2.4.

\subsection{Experimental design}

The DOE software provides a platform for the design of the experimental runs. In accordance with the DOE software, the optimum operating conditions must be established with the aim of eliminating the systematic error and by estimate the error and decreasing the number of experiments and the analysis of the significance relative to several affecting factors in terms of their multifaceted interaction (20). In the present study, the Central Composite Design (CCD) was employed since it is the most commonly used with RSM. Among several classes of response surface design such as the Central Composite Design, the Box-Behnken design, Hybrid design, and a three-level factorial, in the present study like most of the other similar studies, the central composite design (CCD) was employed since it is most commonly used with RSM (21). CCD was used to study the three different factors such as antibiotic concentration (A), dose of catalyst (B), and contact time (C), which were enclosed by antibiotic concentration (50-150 mg/L), contact time (60-120 min), ZnO dose (200-400 mg/L) and WO dose (100-200 mg/L) to evaluate the response. The design consists of $2 \mathrm{k}$ factorial points augmented by a $2 \mathrm{k}$ axial points and a center point, where $\mathrm{k}$ is the number of variables and the range of the mentioned parameter are displayed in Table 1. The variables were considered at three levels, 1 (minimum), 0 (central) and 1 (maximum), which were assessed based on the full face-centered CCD experimental plan. In total, 20 experimental runs were performed and 5 runs were repeated, in order to validate the accuracy of experimental runs.

Table 1. Experimental range and levels of the independent variables

\begin{tabular}{|l|l|l|l|}
\hline \multirow{2}{*}{ Variables } & \multicolumn{3}{|c|}{ Range and Level } \\
\cline { 2 - 4 } & -1 & 0 & +1 \\
\hline Antibiotic concentration $(\mathrm{mg} / \mathrm{L})$ & 50 & 100 & 150 \\
\hline Catalyst concentration of $\mathrm{ZnO}(\mathrm{mg} / \mathrm{L})$ & 200 & 300 & 400 \\
\hline Catalyst concentration of $\mathrm{WO}_{3}(\mathrm{mg} / \mathrm{L})$ & 100 & 150 & 200 \\
\hline Reaction time $(\mathrm{min})$ & 60 & 90 & 120 \\
\hline
\end{tabular}

\subsection{Research Ethics}

This study was approved by the Ethics Committee at Kermanshah University of Medical Sciences (approval number 94127).

\subsection{Mathematical Modeling}

RSM, which has been acknowledged as an effective statistically sound method for optimizing the parameter of the processes and assessment for fitting the model. In present study, RSM was applied with respect to identifying the independent variable and to determine if its interaction affect elicits the desired response. A model in the form of Eq. 1 describes how the RSM fits the experimental data and elaborates about the optimization, and the coefficient for the model was calculated. In order to identify the input, response, as well as the quadratic and linear equation models for predicting the optimal variable, the following was used: $Y=\beta_{0}+\beta_{i} X_{i}+\beta_{j} X_{j}+\beta_{i} X_{i}^{2}+\beta_{j j} X_{j}^{2}+\beta_{i j} X_{i} X_{j}+\ldots$

Where: $\mathrm{Y}, \mathrm{i}, \mathrm{j}, \beta, \mathrm{X}$ shall be considered as the process response, linear coefficient, quadratic coefficient, regression coefficient, and coded independent variables, respectively (20). A multiple regression analysis was used in order to analyze the coefficient variables. Model terms are chosen or neglected in accordance with the probability of error $(\mathrm{P})$ value with a 0.95 of confidence level. The statistical results that were obtained by means of CCD were surveyed by an analysis of variance (ANOVA). The analyses of the data, the experimental design, and the operative optimization of the interaction effect of independent variables on the response were done by design expert software. The results of the experimental data were illustrated using a 3 dimensional plots diagram with respect to the simultaneous effect of variables on the response.

\section{Results}

\subsection{Statistical analysis}

In the present study, CCD was selected for determining the relationship between variables and their response. The variables (A, B and C) are listed in terms of actual and coded units and are illustrated in Table 2 . The number of 20 experimental runs that were performed according to Table 2. The reduction model illustrates in terms of the coded factors with significant model terms and the ANOVA results are presented in Table 3 . The results achieved from the ANOVA analysis were used to determine the applicable level of significance. The significance of the model term 
has been determined via the p-value and the F-Value that were used for response. Meanwhile, the value of probability $>\mathrm{F}$, indicates that the corresponding models and the individual coefficients are more significant. In this study, the higher significance of corresponding model were implied with respect to the larger amount of $\mathrm{F}$-value and smaller amount of probability. The probability value was found to be quite low $(0.000)$, which implies that the term was significant for the model. With respect to equation addressed here, by increasing antibiotic concentration, the COD removal decreased incrementally with increased units of contact time as well as the dose of the catalyst led to an increasing of COD removal. The fitting model has been verified according to the predicted model via the correlation coefficient, $\mathrm{R}^{2}$, adjusted $\mathrm{R}^{2}$, and predicted $\mathrm{R}^{2}$ between the experimental and the predicted model values (Table 3). The correlation coefficients, $\mathrm{R}^{2}$, adjusted $\mathrm{R}^{2}$, and the predicted $\mathrm{R}^{2}$ are near to one another and close to 1.0. In the $\mathrm{UV} / \mathrm{WO}_{3}$ process, the predicted $\mathrm{R}^{2}$ and adjusted $\mathrm{R}^{2}$ were found to be 0.927 and 0.946 , respectively. In the $\mathrm{UV} / \mathrm{ZnO}$ process, the predicted $\mathrm{R}^{2}$ and adjusted $\mathrm{R}^{2}$ were found to be 0.945 and 0.955 , respectively. The validity and reliability of this analysis was determined with adequate precision and it should be valued at 4 or more. There was adequate precision of present study scoring between 35.55 and 45.57 for $\mathrm{UV} / \mathrm{ZnO}$ and $\mathrm{UV} / \mathrm{WO}_{3}$, respectively, and it was remarkably found to be greater than 4 in value, which meant the proper validity of the analysis was supported.

Table 2. The Experimental condition and design expert software result of this study

\begin{tabular}{|l|l|l|l|l|l|l|}
\hline Run & Antibiotic concentration $(\mathrm{mg} / \mathrm{L})$ & Contact time $(\mathrm{min})$ & $\mathrm{ZnO}(\mathrm{mg} / \mathrm{L})$ & $\mathrm{WO}_{3}(\mathrm{mg} / \mathrm{L})$ & \multicolumn{2}{|l|}{ COD removal (\%) } \\
\hline 1 & 75 & 60 & 300 & 150 & $\mathrm{UV} / \mathrm{ZnO}$ & $\mathrm{UV} / \mathrm{WO}_{3}$ \\
\hline 2 & 50 & 120 & 400 & 200 & 54.1 & 72.4 \\
\hline 3 & 75 & 90 & 300 & 150 & 79.6 & 91.3 \\
\hline 4 & 75 & 90 & 200 & 100 & 58.3 & 76.2 \\
\hline 5 & 100 & 120 & 400 & 200 & 46.6 & 67.4 \\
\hline 6 & 100 & 120 & 200 & 100 & 62.3 & 70.8 \\
\hline 7 & 50 & 60 & 200 & 100 & 45.4 & 56.3 \\
\hline 8 & 50 & 120 & 200 & 100 & 56.5 & 70.2 \\
\hline 9 & 100 & 60 & 200 & 100 & 60.4 & 74.4 \\
\hline 10 & 75 & 120 & 300 & 150 & 40.6 & 53.6 \\
\hline 11 & 75 & 90 & 400 & 200 & 64.4 & 77.6 \\
\hline 12 & 50 & 90 & 300 & 150 & 69.5 & 84.3 \\
\hline 13 & 50 & 60 & 400 & 200 & 67.2 & 83.5 \\
\hline 14 & 100 & 60 & 400 & 200 & 75.2 & 88.1 \\
\hline 15 & 100 & 90 & 300 & 150 & 57.6 & 70.4 \\
\hline
\end{tabular}

Table 3. The ANOVA result for the equation of the design expert software

\begin{tabular}{|l|l|l|l|l|l|l|l|}
\hline Processes & $\begin{array}{l}\text { Modified equations with } \\
\text { significant }\end{array}$ & $\begin{array}{l}\text { Type of } \\
\text { Model }\end{array}$ & $\begin{array}{l}\text { Adeq. } \\
\text { precision }\end{array}$ & $\mathrm{R}^{2}$ & $\begin{array}{l}\text { Adjusted } \\
\mathrm{R}^{2}\end{array}$ & $\begin{array}{l}\text { Predicted } \\
\mathrm{R}^{2}\end{array}$ & $\begin{array}{l}\mathrm{p}- \\
\text { value }\end{array}$ \\
\hline $\mathrm{UV} / \mathrm{WO}_{3}$ & $\begin{array}{l}-75.34-9-9.39 \mathrm{~A}+7.65 \mathrm{~B} \\
+1.94 \mathrm{C}-3.4 \mathrm{~B} 2\end{array}$ & Quadratic & 35.55 & 0.958 & 0.946 & 0.927 & 0.000 \\
\hline $\mathrm{UV} / \mathrm{ZnO}$ & $\begin{array}{l}2.81 \mathrm{C}+9.47 \mathrm{~B}+8.34 \mathrm{~A}- \\
58.86\end{array}$ & Linear & 45.47 & 0.962 & 0.955 & 0.945 & 0.000 \\
\hline
\end{tabular}

\subsection{Ultrasound process (Effect of antibiotic concentration on COD removal)}

It was observed that the efficiency of the ultrasound process increased with a decrease in the concentration of the PG $(\mathrm{p}<0.05)$. The maximum degradation was achieved with $50 \mathrm{mg} / \mathrm{l}$ of PG. Figure 1 depicted the Penicillin $\mathrm{G}$ concentration according to influent and effluent of COD. The maximum and minimum COD removal $(24.82 \%$ and $12.45 \%$ ) were observed at the antibiotic concentration was at $50 \mathrm{mg} / \mathrm{l}$ and $100 \mathrm{mg} / \mathrm{l}$, respectively. Also, with respect to the ANOVA analysis and the Duncan test in SPSS version 18 software, the COD removal in different antibiotic concentration was found to be significant $(\mathrm{p}<0.05)$.

\subsection{Photocatalytic process}

3.3.1. Effect of contact time on the COD removal:

The effect of the variables on COD removal in terms of 3D plot is presented in Figure 2 and 3. According to these obtained results, a high rate of decomposition is observed at the initial time of photodegradation. For example, in initial antibiotic concentration of $50 \mathrm{mg} / \mathrm{L}$ and $\mathrm{WO}_{3}$ dose of $100 \mathrm{mg} / \mathrm{L}$, by increasing the contact time from 60 to 120 minutes, the COD removal increased by nearly $4.2 \%$. 


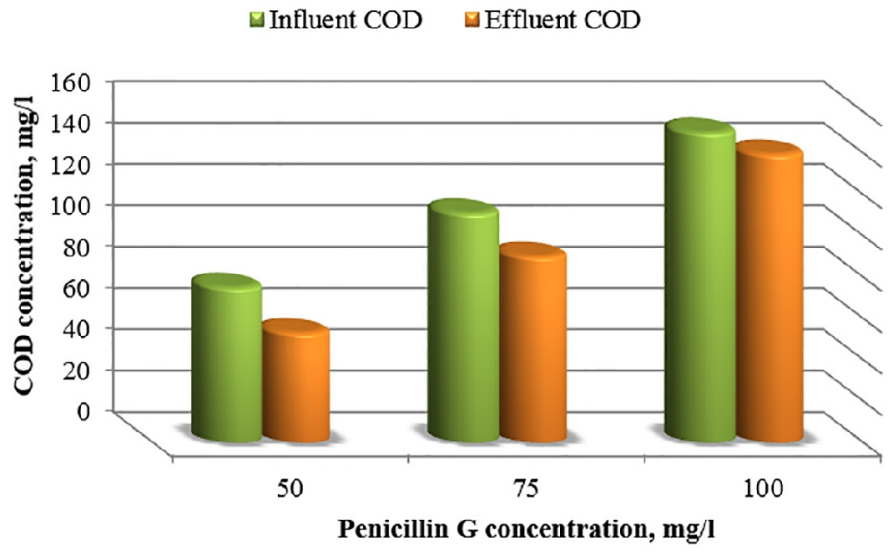

Figure 1. The influent and effluent COD Concentration in Ultrasound process
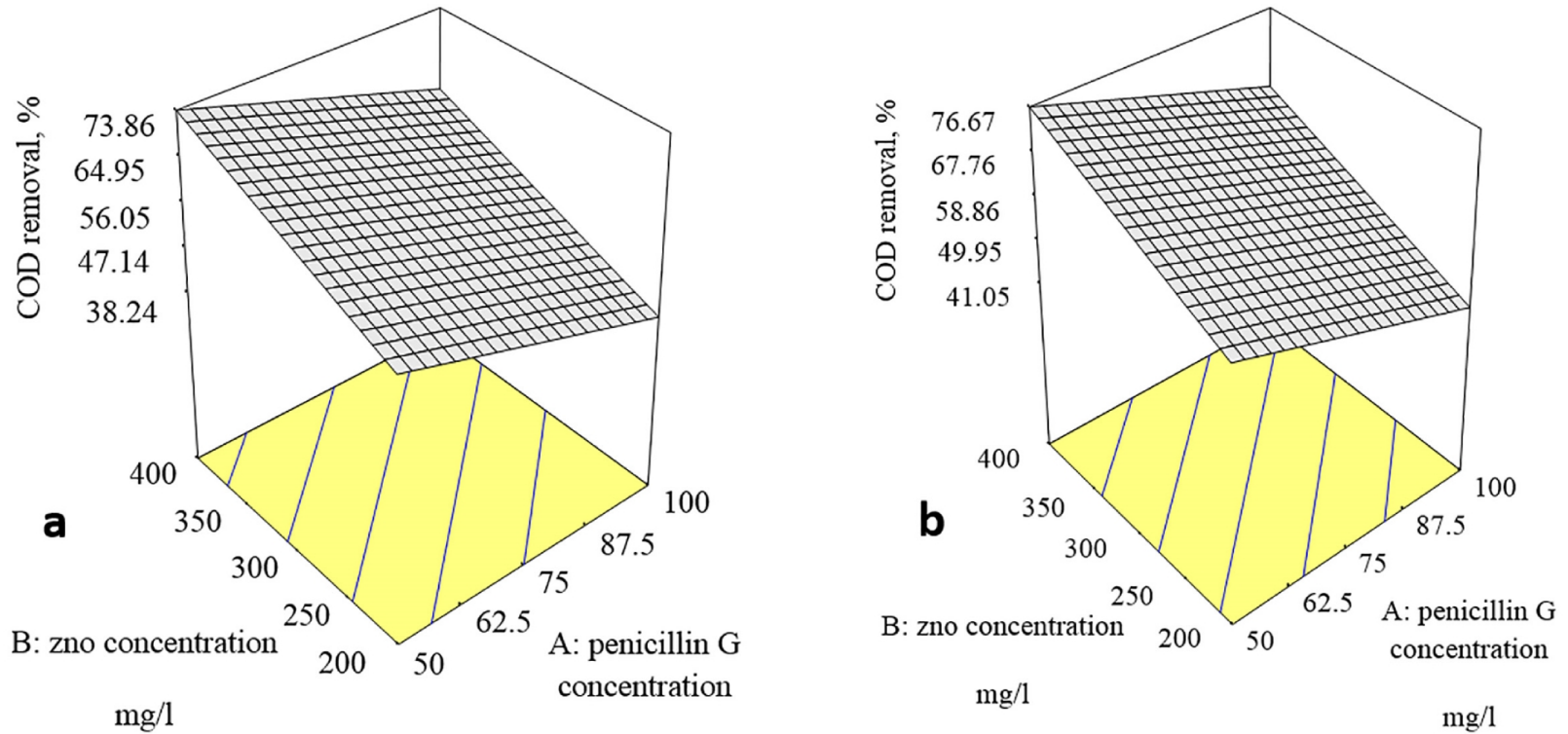

$\mathrm{mg} / \mathrm{l}$

$\mathrm{mg} / \mathrm{l}$
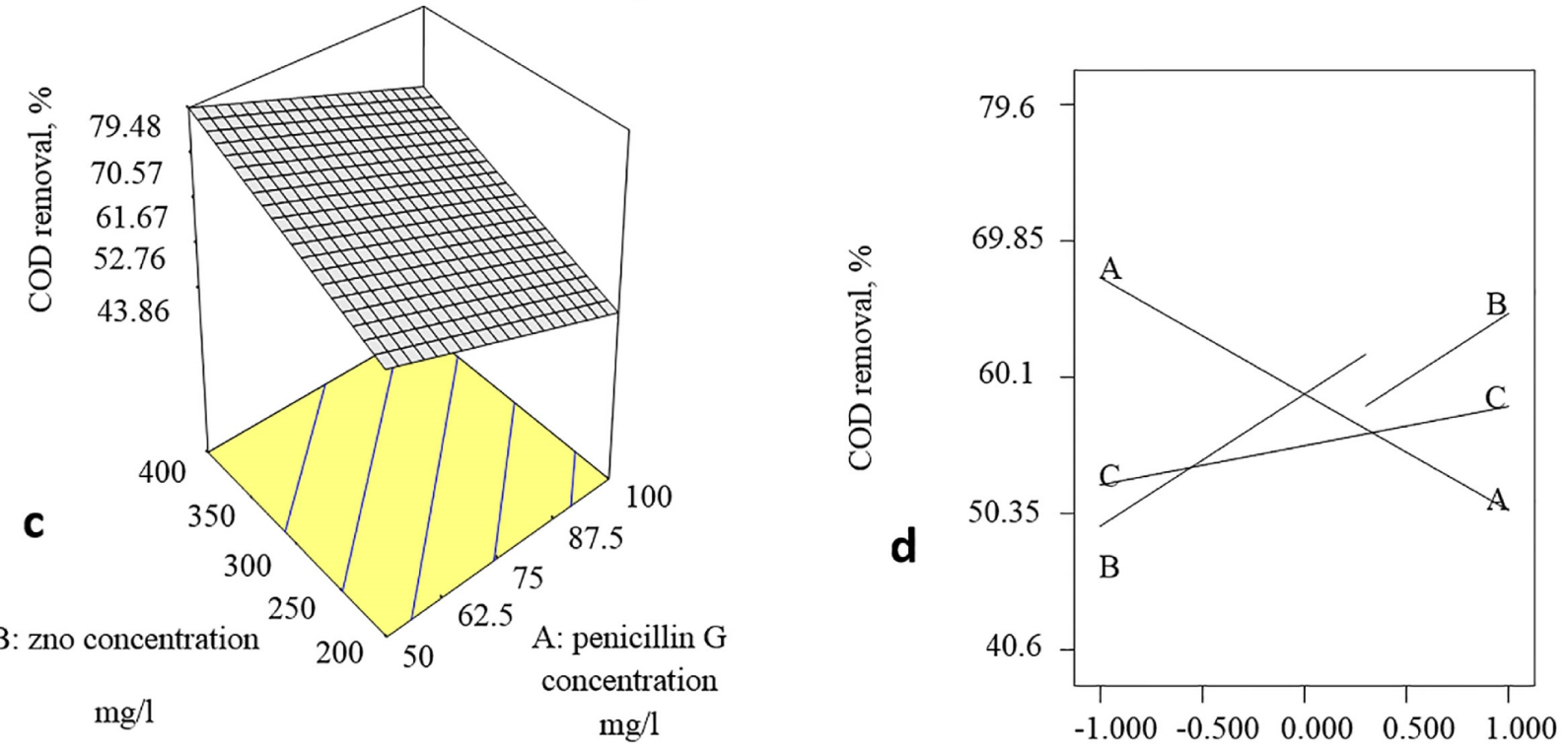

Figure 2. Response surface plot for COD Removal of Penicillin G with UV/ZnO in contact time of (a) 60 min (b) 90 min (c) 120 min (d) Perturbation plot for COD removal rate 




B: wo 3 Concentration, $125100 \quad 62.5$ A: penicillin G $\mathrm{mg} / 1$
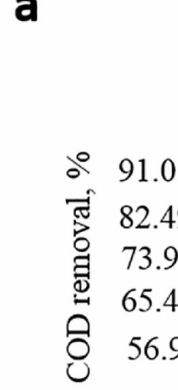

B: wo $_{3}$ concentration, $\mathrm{mg} / \mathrm{l}$ concentration, $\mathrm{mg} / 1$


Figure 3. Response surface plot for COD Removal of Penicillin G with $U V / \mathrm{WO}_{3}$ in Reaction time of (a) 60 min (b) $90 \mathrm{~min}$ (c) $120 \mathrm{~min}$ (d) Perturbation plot for COD removal 3-4- Process optimization and verification

3.3.2. Effect of the initial antibiotic concentration and of $\mathrm{ZnO}$ and $\mathrm{WO}_{3}$ dose on the $\mathrm{COD}$ removal:

A three dimensional plot of the model with respect to the simultaneous effect of the antibiotic concentration, $\mathrm{WO}_{3}$ dose, and $\mathrm{ZnO}$ dose over different contact times are shown in Figures 2 and 3. The initial concentration of PG was an effective parameter on the photodegradation efficiency. By increasing the initial concentration of PG up to 100 $\mathrm{mg} / \mathrm{L}$, the removal efficiency decreased. For instance, for a contact time of 120 minutes in $\mathrm{UV} / \mathrm{ZnO}$, the COD removal for the initial antibiotic concentration of $50 \mathrm{mg} / \mathrm{L}(79.6 \%)$ was more than $100 \mathrm{mg} / \mathrm{L}(62.3 \%)$. By exploring the effect of the catalyst dose on process efficiency; it was also revealed by increasing of catalyst dosage that the performance of photocatalytic has advanced. The maximum COD (79.6\% and $91.3 \%)$ removal efficiency was observed at the $\mathrm{ZnO}$ dosage of $600 \mathrm{mg} / 1$ and $\mathrm{WO}_{3}$ dosage of $200 \mathrm{mg} / \mathrm{l}$, respectively. Meanwhile, the lowest predicted removal efficiency of COD $(40.6 \%)$ for $\mathrm{UV} / \mathrm{ZnO}$ and $(53.6 \%)$ for $\mathrm{UV} / \mathrm{WO}_{3}$ was obtained at the contact time of 120 minutes and the PG concentration of $50 \mathrm{mg} / \mathrm{l}$. The influence of the antibiotic concentration and the catalyst dose on COD removal efficiency was found to be more significant than the variable of contact time (p $<$ $0.05)$.

\subsection{Process optimization and verification}

The graphical optimization of the overlay plot demonstrates that the regions meet the proposed criteria. The optimum region corresponding to the COD removal was higher than $70 \%$. The yellow area was the region that satisfies the constraints. The optimal region enclosed by the the Penicillin G concentration $(75 \mathrm{mg} / \mathrm{l})$ and $\mathrm{WO}_{3}$ dose 
(150 mg/l) in $\mathrm{UV} / \mathrm{WO}_{3}$; and Penicillin $\mathrm{G}$ concentration $(50 \mathrm{mg} / \mathrm{l})$ and $\mathrm{ZnO}$ dose (400) in $\mathrm{UV} / \mathrm{ZnO}$. In order to validate the accuracy of the models, a point within the optimum region was chosen (conditions shown by flags in Figure 4). The actual value along with the predicted value response was compared. The accuracy of optimum condition through DOE software was investigated by rxamining the standard deviation for each response, and very close to the actual values to predict model values were obtained.

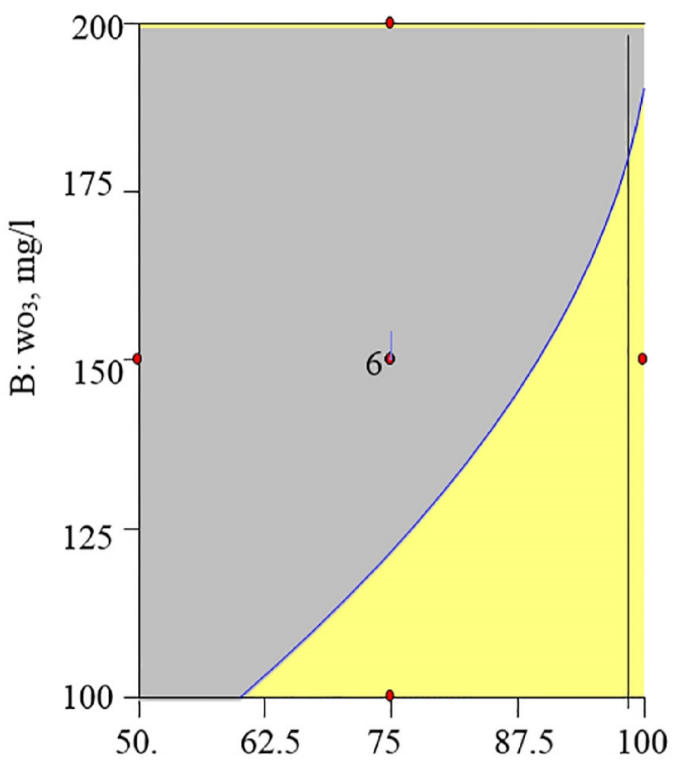

a

\section{A: penicillin $\mathrm{G}$ concentration, $\mathrm{mg} / 1$}

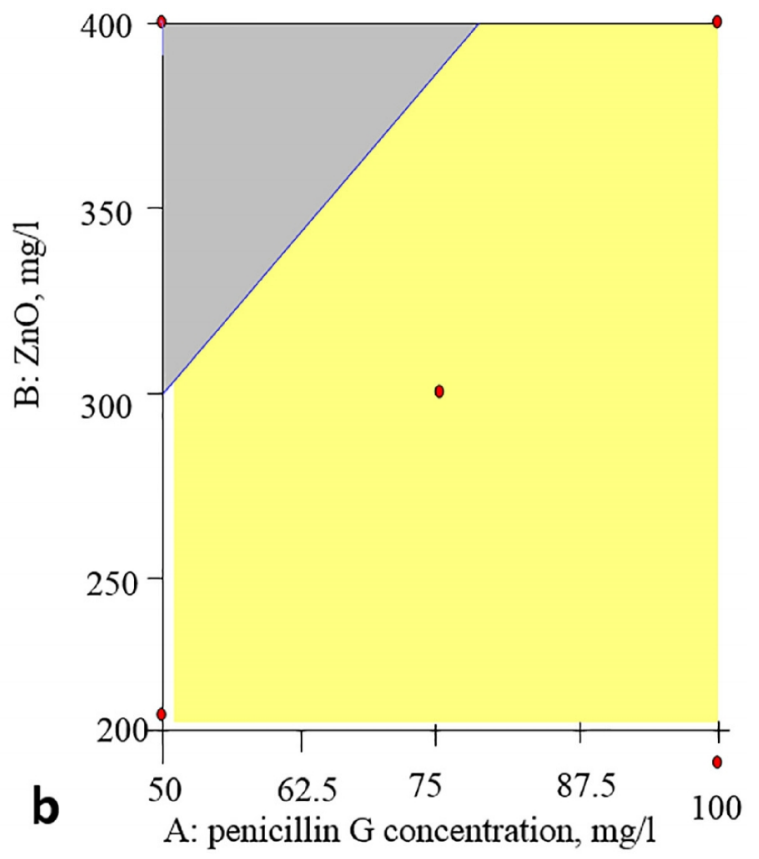

A: penicillin $\mathrm{G}$ concentration, $\mathrm{mg} / 1$

Figure 4. Overlay plot for optimal region (a) $\mathrm{WO} 3$ (b) $\mathrm{ZnO}$

\section{Discussion}

Generally, it can be concluded that the sonophotocatalytic degradation could achieve high COD removal efficiency in a low amount of contact time and with a low catalyst dosage. Based on results obtained, the COD removal efficiency significantly increased along with an increase in the catalyst dosage $(p<0.05)$. As a result, when the PG was decreased, a lesser catalyst dose was required. An inverse relationship between the PG concentration and the COD removal was observed in this study. This supports the assertion that all three variables have significant effects on COD removal. Ultrasonic pre-treatment could not achieve a high level of COD removal. It may be attributed to low amount of hydroxyl radical $(\mathrm{OH} \bullet)$ generation. The effectiveness of this ultrasonic process is associated with the water matrix. According to various studies, the increasing of ionic strength can accelerate the free radical activity in an aqueous solution and cause increased efficiency of COD removal. Hence, the low COD removal may be attributed to the use of deionized water $(15,22)$.

\subsection{Effect of initial antibiotic concentration}

Based on the results that were obtained, the initial concentration of PG was an effective parameter for predicting the photodegradation efficiency. By increasing the initial concentration of PG up to $100 \mathrm{mg} / \mathrm{L}$, the removal efficiency decreased. The catalyst dose and contact time had a similar effect on the COD removal in the photocatalytic reactor. The reaction of the antibiotic with the hydroxyl radicals in the low concentration lead to degradation improvement due to free radicals (23). In the high concentration of PG, the active site has been covered through antibiotic ions that cause a reduction in the generation of hydroxyl radicals on the surface of the catalyst (24). Therefore, the high concentration of PG, absorbs photons from UV light readily, and as a result, it tends to reduce the UV photons for catalyst activation (25). Another reason may be attributed to the intervention of intermediate by-products, which are generated during the degradation of antibiotic molecules.

\subsection{Effect of contact time}

As shown in Table 3, the increasing contact time enhanced the COD removal. This may be due to the exiting $\mathrm{ZnO}$ and $\mathrm{WO}_{3}$ particles, and increasing of hole creation in the catalyst surface and as a result, leading to the incremental absorption surface area and as well as COD removal enhancement (26). A high rate of degradation was observed in 
the first 60 min of photodegradation and after that the rate of PG degradation became slower. This is probably due to a large amount of available active sites in the beginning. Additionally, the generated intermediate organic compounds in the photochemical degradation leads to decreasing the COD removal.

\subsection{Effect of catalyst dose}

According to the results obtained, by increasing the catalyst dosage the rate of PG decomposition by absorbing more photons on its surface was also increased. So, the available active sites increased and as well as causing an increasing of the absorbed antibiotic molecules $(16,24,27)$. Contrastingly, the content of $\mathrm{ZnO}$ and $\mathrm{WO}_{3}$ has significantly influenced the COD removal $(\mathrm{p}<0.05)$. Generally, the slight increase in catalyst dose leads to a reduction of reaction time in the photocatalytic process. The catalyst has two opposite effects on the process efficiency including the COD removal increment due to increasing of available site and decreasing of COD removal due to the solution turbidity increasing and the decrease in UV light penetration. Hence, the optimal set up and operation of the photocatalytic reactor should be considered in order to ensure the photon absorption and preventing extra catalyst use (4).

\subsection{The effect of UV light}

The organic matter photolysis by the photocatalytic processes through optimal simulation semiconductor and subsequently by the electron-hole pair's generation in the surface of catalyst. High oxidative potential holes (h valence band) in the catalyst provide direct oxidation of the organic matter with the intermediate product. Likewise, the reactive hydroxyl radicals are produced by the water catalysis or the reaction between holes with hydroxyl radical $(\mathrm{OH})$. The hydroxyl radical is a strong non-selective oxidant for organic compound degradation. Also, electrons in the conduction band generated the hydroxyl radicals, which are the principal reason for organic matter mineralization (16).

\section{Conclusions}

In the present study, PG has been successfully degraded by the sonophotocatalyst. The advantages of the processes are a high rate, a lesser cost for wastewater treatment in a UV/ZnO process in comparison to other advanced oxidation processes, a lack of sludge generation, simple operation, and an industrial scale applicability. The maximum COD removal in UV/ $\mathrm{WO}_{3}$ was found to be $91.3 \%$ in catalyst dose of $200 \mathrm{mg} / \mathrm{L}$, contact time of 120 minutes and antibiotic concentration of $50 \mathrm{mg} / \mathrm{L}$. Finally, it can be deduced that the effect of the combined photochemical processes in water, direct photolysis by UV radiation, acoustic cavitation, and hydroxyl radicals have been identified as main reason for high COD removal in this study. The photocatalytic process has been confirmed as an applicable technology and is an environmentally friendly process that can be used extensively, in comparison to the high financial component and possibility of creating poisonous intermediate byproduct generation in the chemical process, which would be caused by employing of photocatalytic processes to solve the problem.

\section{Acknowledgments:}

The authors gratefully acknowledge the Research Council of Kermanshah University of Medical Sciences (Grant Number: 94127) for its financial support.

\section{Conflict of Interest:}

There is no conflict of interest to be declared.

\section{Authors' contributions:}

All authors contributed to this project and article equally. All authors read and approved the final manuscript.

\section{References:}

1) Nasuhoglu D, Rodayan A, Berk D, Yargeau V. Removal of the antibiotic levofloxacin (LEVO) in water by ozonation and TiO2 photocatalysis. Chem Eng J. 2012; 189(190): 41-8. doi:10.1016/j.cej.2012.02.016.

2) Martinez JL. Environmental pollution by antibiotics and by antibiotic resistance determinants. Environ Pollut. 2009; 157(11): 2893-902. doi:10.1016/j.envpol.2009.05.051. PMID: 19560847.

3) Jeong J, Song W, Cooper WJ, Jung J, Greaves J. Degradation of tetracycline antibiotics: Mechanisms and kinetic studies for advanced oxidation/reduction processes. Chemosphere. 2010; 78(5): 533-40. doi: 10.1016/j.chemosphere.2009.11.024. PMID: 20022625.

4) Elmolla $\mathrm{S}$, Chadhuri M. Comparison of different advanced oxidation processes for treatment antibiotic aqueous solution. Desalination. 2010; 256(1-3): 43-7. doi: 10.1016/j.desal.2010.02.019. 
5) Peerayeh SN, Karmostaji A, Sarasiabi SS, Javadpour S, Davoodian P, Moradi N. In Vitro Activity of Tigecycline and Colistin against clinical isolates of Acinetobacter baumannii in Hospitals in Tehran and Bandar-Abbas, Iran. Electron Physician. 2014; 6(3): 919-24. doi: 10.14661/2014.919-924. PMID: 25763168, PMCID: PMC4324296.

6) Emad SE, Chaudhur M. The feasibility of using combined $\mathrm{TiO} 2$ photocatalysis-SBR process for antibiotic wastewater treatment. Desalination. 2011; 272(1-3): 218-24. doi:10.1016/j.desal.2011.01.020.

7) Sharif MR, Soltani B, Moravveji A, Erami M, Soltani N. Prevalence and Risk Factors associated with Extended Spectrum Beta Lactamase Producing Escherichia coli and Klebsiella pneumoniae Isolates in Hospitalized Patients in Kashan (Iran). Electron Physician. 2016; 8(3): 2081-7. doi: 10.19082/2081. PMID: 27123215, PMCID: PMC4844472.

8) Peterson JW, Petrasky LJ, Seymour MD, Burkhart RS, Schuiling AB. Adsorption and breakdown of penicillin antibiotic in the presence of titanium oxide nanoparticles in water. Chemosphere. 2012; 87(8): 911-7. doi: 10.1016/j.chemosphere.2012.01.044. PMID: 22342282.

9) Saghafinia MS, Emadian SM, Vossoughi M. Performances Evaluation of Photo-Fenton Process and Sonolysis for the Treatment of Penicillin G FormulationEffluent. Procedia Environmental Sciences. 2011; 8: 202-8. doi:10.1016/j.proenv.2011.10.033.

10) Puckowski A, Mioduszewska K, Łukaszewicz P, Borecka M, Caban M, Maszkowska J, et al. Bioaccumulation and analytics of pharmaceutical residues in the environment: A review. J Pharm Biomed Anal. 2016; pii: S0731-7085(16)30111-x. doi: 10.1016/j.jpba.2016.02.049. PMID: 26968887.

11) Taghavi SM, Momenpour M, Azarian M, Ahmadian M, Souri F, Taghavi SA, et al. Effects of Nanoparticles on the Environment and Outdoor Workplaces. Electron Physician. 2013; 5(4): 706-12. doi: 10.14661/2013.706-712. PMID: 26120406, PMCID: PMC4477780.

12) Dobaradaran S, Nabizadeh R, Mahvi A, Mesdaghinia A, Naddafi K, Yunesian M, et al. Survey on degradation rates of trichloroethylene in aqueous solutions by ultrasound. Journal of Environmental Health Science \& Engineering. 2010; 7(4): 307-12.

13) Seungmin Na, Sanghyun Cho, Seban Lee, Seungkwan Hong, Jeehyeong Khim. Addition of sonochemical reactor to the solar photocatalytic compound parabolic concentrators system. Japanese Journal of Applied physics. 2011; 50: 7-14. doi: 10.1143/JJAP.50.07HE14.

14) Yuan F, Hu C, Hu X, Qu J, Yang M. Degradation of selected pharmaceuticals in aqueous solution with UV and UV/H2O2. Water Res. 2009; 43(6): 1766-74. doi:10.1016/j.watres.2009.01.008. PMID: 19232423.

15) Klavarioti M, Mantzavinos D, Kassinos D. Removal of residual pharmaceuticals from aqueous systems by advanced oxidation processes. Environ Int J. 2009; 35(2): 402-17. doi:10.1016/j.envint.2008.07.009. PMID: 18760478.

16) Homem V, Santos L. Degradation and removal methods of antibiotics from aqueous matrices-A review. J Environ Manage. 2011; 92(10): 2304- 47. doi:10.1016/j.jenvman.2011.05.023. PMID: 21680081.

17) Kümmerer K. Antibiotics in the aquatic environment--a review--part I. Chemosphere. 2009; 75(4): 417- 34. doi: 10.1016/j.chemosphere.2008.11.086. PMID: 19185900.

18) Michael I, Rizzo L, McArdell CS, Manaia CM, Merlin C, Schwartz T, et al. Urban wastewater treatment plants as hotspots for the release of antibiotics in the environment: A review. Water Res. 2013; 47(3): 957 95. doi: 10.1016/j.watres.2012.11.02. PMID: 23266388.

19) APHA, AWWA, WPCE. Standard Methods for The Examination of Water and Wastewater. 22th ed APHA. 2008.

20) Pirsaheb M, Mohamadi M, Mansouri AM, Zinatizadeh AAL, Sumathi S, Sharafi K. Process modeling and optimization of biological removal of carbon, nitrogen and phosphorus from hospital wastewater in a continuous feeding \& intermittent discharge (CFID) bioreactor. Korean J Chem Eng. 2015; 32(7): 1340-53. doi: 10.1007/s11814-014-0365-z.

21) Khuri AI, Cornell JA. Response surfaces: design and analyses, Marcel Dekker, New York (1996).

22) Sanchez-Prado L, Barro R, Garcia-Jares C, LlompartM, Lores M, Petrakis C, et al. Sonochemical degradation of triclosan in water and wastewater. Ultrasonics Sonochemistry. 2008; 15(5): 689-94. doi: 10.1016/j.ultsonch.2008.01.007. PMID: 18321752.

23) Verma A, Kaur H, Dixit D. Photocatalytic, Sonolytic and sonophotocatalytic degradation of 4-Chloro-2nitro phenol. Archive of environmental protection. 2013; 39(2): 17-28. doi: 10.2478/aep-2013-0015.

24) Yang L, Yu LE, Ray MB. Degradation of paracetamol in aqueous solutions by TiO2 photocatalysis. Water Res. 2008; 42(13): 3480-8. doi:10.1016/j.watres.2008.04.023. PMID: 18519147. 
25) Sioi M, Bolosis A, Kostopoulou E, Poulios I. Photocatalytic treatment of colored wastewater from medical laboratories: photocatalytic oxidation of hematoxylin. Journal of Photochemistry and Photobiology A: Chemistry. 2006; 184(1): 18-25. doi: 10.1016/j.jphotochem.2006.03.028.

26) Konstantina T, Elpida, P. Modeling of arsenic immobilization by zero valent iron. Soil Biology. 2007; 43: 356-67. doi: 10.1016/j.ejsobi.2007.03.011.

27) Kashif N, Ouyang F. Parameters effect on heterogeneous photocatalysed degradation of phenol inaqueous dispersion of TiO2. J Environ Sci (China). 2009; 21(4): 527-33. doi: 10.1016/S1001-0742(08)62303-7. PMID: 19634430. 